\title{
Normative bone mineral density data at multiple skeletal sites in Indian subjects
}

\author{
Annu Makker • Geetanjali Mishra • \\ Balendra Pratap Singh • Arvind Tripathi • \\ Man Mohan Singh
}

Received: 24 December 2007 / Accepted: 21 July 2008 / Published online: 20 September 2008

(C) The Author(s) 2008. This article is published with open access at Springerlink.com

\begin{abstract}
Summary Age-related change in bone mineral density (BMD) varied according to skeletal site in Indian subjects. A larger proportion of subjects was classified as osteoporotic and osteopenic using the Caucasian database than newly derived peak BMD values at most skeletal sites. Results establish useful normative data for reliable interpretations of individual dual-energy X-ray absorptiometry (DEXA) values

Introduction Osteoporosis is believed to occur at a relatively younger age in the Indian population. With increasing knowledge on significant differences in BMD between various racial groups, there is increased emphasis for the use of population-specific reference database.

Methods BMD at multiple skeletal sites was measured using DEXA (Prodigy, Lunar) in 615 Indian women (20-86 years) and 489 Indian men (20-83 years). Best-fit models were drawn for each skeletal site. Osteopenia and osteoporosis diagnosis rates were calculated using Caucasian and derived Indian peak BMD values.

Results Age-related change in BMD varied with skeletal site in both sexes. Peak BMD in women was observed between 31 and 40 years of age at the hip, spine, and radius
\end{abstract}

A. Makker $\cdot$ G. Mishra $\cdot$ M. M. Singh $(\bowtie)$

Division of Endocrinology, Central Drug Research Institute,

Lucknow 226001 , India

e-mail:singhmm@rediffmail.com

B. P. Singh · A. Tripathi

Department of Prosthodontics, CSM Medical University,

Lucknow 226003 , India

Present address:

G. Mishra

Department of Zoology, University of Lucknow,

Lucknow 226 007, India
$33 \%$ and between 20 and 30 years at the ultradistal radius. Peak BMD in men was attained between 20 and 30 years at the hip and radius $33 \%$ and between 31 and 40 years at the spine and ultradistal radius. A larger proportion of Indian subjects was classified as osteoporotic and osteopenic based on the Caucasian database than newly derived Indian peak BMD values at all skeletal sites except radius $33 \%$ and femoral neck in females above 40 years of age.

Conclusion Results establish useful normative data for the Indian population for reliable interpretations of individual DEXA values.

Keywords Osteoporosis · BMD-DEXA · Lunar Prodigy · Normative data $\cdot$ Indian population

\section{Introduction}

Osteoporosis, a silently progressing metabolic bone disease that leads to loss of bone mass, is widely prevalent in India, and osteoporotic fractures are a common cause of morbidity and mortality in adult Indian women and men [1]. Expert groups peg the number of osteoporosis patients in India at approximately 26 million with the numbers projected to increase to 36 million by the year 2013 [2]. Although relatively little is known about osteoporotic risk factors in women in the Indian subcontinent, osteoporotic fractures usually occur 10-20 years earlier in Indian women and men than their western Caucasian counterparts [3]. It has also been suggested that osteopenia and osteoporosis may occur at a relatively younger age in the Indian population $[4,5]$.

Age-related change in bone mineral density (BMD) and fracture risk have been associated with many factors including heredity, race, region, environment, nutrition, lifestyle, etc. [6, 7] and there are significant differences in 
BMD between peer age groups of different sexes and areas [7, 8]. Reference ranges may thus vary in different populations $[9,10]$. The World Health Organization densitometric definition of osteoporosis, based on fracture risk, strictly pertains only to postmenopausal Caucasian women [11]. However, due to lack of adequate prospective data, quantitative relationship between BMD and fracture risk and treatment guidelines designed for Caucasian women have routinely been applied worldwide to non-Caucasian women and even men, despite the lack of any direct evidence and marked differences in skeletal size, height, body weight, etc. [12]. Based on currently available data, it is now becoming increasingly apparent that there are significant differences in BMD between various racial groups. Locally derived reference values are thus important to avoid false-positive or false-negative findings during work-up in patients evaluated for osteoporosis [13]. Assessment of risk of osteoporosis in Asian women by comparing their BMD with the reference Caucasian population may, therefore, have limited validity primarily because of the influence of skeletal size on such measurements.

The present study was aimed to (a) establish normative data for BMD at the three major skeletal sites of osteoporotic fractures viz. total hip including femoral neck, Ward's triangle and trochanter, lumbar spine and forearm $[11,14]$ in healthy adult Indian women and men, stratified in 10-year age bands, using dual-energy X-ray absorptiometry (DEXA); (b) compare the BMD of Indian females and males with the US/ European BMD values provided by the manufacturer [15, 16, and personal communication]; (c) examine correlation between BMD and age; (d) establish osteoporosis cut off limits for Indian women and men for calculation of $T$ scores that allowed more realistic categorization of people as normal, osteopenic, or osteoporotic than with the use of the manufacturer's reference range based on Caucasian population; and (e) define prevalence of osteoporosis at different skeletal sites in postmenopausal women and men $>50$ years of age. Pertinently, few earlier studies using DEXA have reported lower mean BMD at the spine and hip in Indian women than the reference North American and European population [17-20]. In addition, reports on Indian women and men based on methods such as Singh's index [21], calcaneal index [22], visual assessment [4, 5], quantitative ultrasound [23], digital X-ray radiogrammetry [24], and quantitative computed tomography [25] are also available.

\section{Materials and methods}

\section{Subjects}

In this cross-investigational study, a total of 615 healthy women aged between 20 and 86 years and 489 healthy men aged between 20 and 83 years residing in Lucknow and its surrounding areas were recruited between April 2004 and December 2007. Out of 615 women, 342 were postmenopausal. The recruitment was made in part among the staff of the institute and medical university and lay people contacted by word of mouth. Care was taken to ensure representativeness of the general population with particular regard to the inclusion of subjects belonging to a wide range of socioeconomic strata, body size, and physical activity. The subjects included medical and research professionals; university and school teachers; engineers; medical and research students; nursing staff; technical, administrative, bank, and railway employees; security guards; businessmen; farmers; housewives; and housemaids. All participants were screened using a detailed questionnaire concerning health, daily dietary calcium intake, sun exposure, physical activity level and patterns, occupational activities, and tobacco and alcohol use. Medical, surgical, reproductive, fracture, and low backache history was recorded by one of us (BPS). The study was approved by the Institutional Ethics Committee and informed consent was obtained from all participants. Exclusion criteria were bilateral hip replacement, ankylosing spondylitis, low trauma fracture, primary hyperparathyroidism, hyperthyroidism, hyperprolactinemia, current pregnancy, lactation, bilateral oophorectomy, amenorrhea $\geq 6$ months before the age of 40 years except during pregnancy and lactation, kidney or liver disease, organ transplantation, Paget's disease, malabsorption, history of cancer, current use of hormone/estrogen replacement therapy, and history of immunosuppressant, antiepileptic, bisphosphonate, selective estrogen receptor modulator, calcitonin, or teriparatide usage and was based on information provided by the volunteers.

\section{Anthropometric data}

Body weight and height of each subject were measured with light indoor clothing without shoes at the time of bone densitometry measurement. The body weight was recorded to the nearest tenth of a kilogram using an electronic scale and standing height was measured to the nearest centimeter by a calibrated wall-mounted Harpenden stadiometer with coefficient of variability of $<0.5 \%$. Body mass index (BMI) was calculated as body weight in kilograms divided by height in meters squared.

Bone mineral density measurements

BMD expressed in gram per centimeter squared was measured using DEXA fanbeam bone densitometer (Prodigy, Lunar, Madison, WI, USA) at the (a) total hip including femoral neck, Ward's triangle, and trochanter; 
(b) lumbar spine (L2-L3) in lateral projection; and (c) left forearm including radius 33\% and ultradistal radius (radius UD). As we did not specifically exclude subjects with spinal osteoarthritis or aortic calcification that can confound BMD measurement [26, 27], we assessed the lateral instead of anteroposterior spine, which largely excludes these confounders from the scanning field. All measurements were made by the same operator and none of the scan devices was changed during the study. The in vivo precision was assessed by three repeated BMD measurements in 15 subjects. Percent coefficient of variance ranged from $0.5 \%$ to $1.1 \%$ depending on the measurement site. To ensure reproducibility, the instrument was calibrated daily with hydroxyapatite anthropomorphic spine phantom provided by the manufacturer before use.

Statistical analysis

SPSS 10.0 was used for statistical analysis of the data. BMD at various sites in subjects with age-related change was evaluated and the best-fit model found by a comparison of different regression models for linear, logarithmic, quadratic, cubic, compound, power, growth, and exponential equations. Analysis of variance with Tukey's post hoc test was used to determine differences in BMD among different age groups. All subjects were stratified in 10-year age groups and the BMD, body weight, height, and BMI in each group were reported as the mean and standard deviation (SD). Peak BMD was determined from the age group with the highest mean BMD value and outliers of more or less than $3 \mathrm{SD}$ beyond the main peak BMD were excluded.

The mean BMD for each decade of age at all the skeletal sites was compared with the mean values for Caucasian women and men provided in the Caucasian database supplied by the manufacturer of the densitometer using Student's $t$ test. $T$ scores were calculated using the Caucasian BMD means and standard deviations as well as our newly derived Indian cohort's BMD means and standard deviations using the following equation:

$T$ score $=\frac{\mathrm{BMD}_{\text {subject }}-\text { peak BMD }}{\mathrm{SD}_{\text {peak }}}$.

$T$ score $<-2.5$ was used as the cut off value in the diagnosis of osteoporosis, $T$ score between -2.5 and -1 was diagnostic of low bone mass (osteopenia), and $T$ score $>-1$ was considered as normal [11, 14].

\section{Results}

The anthropometric data of the subjects are shown in Table 1. The study sample was divided into six subgroups according to age for cross-sectional analysis.

Female subjects

Hip

For total hip and its components, peak BMD was observed between ages 31 and 40 years (Tables 2 and 3). Figure 1a-d displays the polynomial regression equations that describe the relationship between age and BMD at each site. The cubic regression model was the simplest model that significantly improved fit to the data at every site except total hip where the quadratic model fitted this criterion. BMD of hip at different sites, viz. Ward's $\left(R^{2}=0.5241, P<\right.$ $0.001)$, femoral neck $\left(R^{2}=0.3667, P<0.001\right)$, trochanter $\left(R^{2}=0.2335, P<0.05\right)$, and total hip $\left(R^{2}=0.3229, P<0.001\right)$ in Indian women was significantly negatively regressed with age. A highly significant negative correlation between age groups and BMD at any site of the hip was found in Indian women $(P<0.001)$. The actual decrease of BMD between the age of peak BMD and 86 years was highest for Ward's triangle $(43 \%$; average change per decade was $8.6 \%$ ) and ranged between $25 \%$ and $29 \%$ for total hip,

Table 1 Anthropometric characteristics in normal Indian women and men

\begin{tabular}{|c|c|c|c|c|c|c|c|c|c|}
\hline \multicolumn{5}{|c|}{ Indian women } & \multicolumn{5}{|c|}{ Indian men } \\
\hline $\begin{array}{l}\text { Age in } \\
\text { years }\end{array}$ & $\begin{array}{l}\text { Total } \\
\text { number }\end{array}$ & Height (cm) & $\begin{array}{l}\text { Body weight } \\
\text { (kg) }\end{array}$ & $\begin{array}{l}\text { BMI }(\mathrm{kg} / \\
\left.\mathrm{m}^{2}\right)\end{array}$ & $\begin{array}{l}\text { Age in } \\
\text { years }\end{array}$ & $\begin{array}{l}\text { Total } \\
\text { number }\end{array}$ & Height (cm) & $\begin{array}{l}\text { Body weight } \\
(\mathrm{kg})\end{array}$ & $\begin{array}{l}\text { BMI }(\mathrm{kg} / \\
\left.\mathrm{m}^{2}\right)\end{array}$ \\
\hline $20-30$ & 114 & $159.83 \pm 4.33$ & $53.13 \pm 7.95$ & $20.87 \pm 3.05$ & $20-30$ & 85 & $172.51 \pm 8.58$ & $65.11 \pm 10.23$ & $21.35 \pm 3.93$ \\
\hline $31-40$ & 99 & $156.36 \pm 5.25$ & $63.31 \pm 9.38$ & $25.98 \pm 4.05$ & $31-40$ & 70 & $170.76 \pm 8.92$ & $72.13 \pm 13.74$ & $24.63 \pm 3.56$ \\
\hline $41-50$ & 119 & $156.34 \pm 5.79$ & $62.17 \pm 9.34$ & $25.59 \pm 3.43$ & $41-50$ & 95 & $171.00 \pm 6.62$ & $71.48 \pm 10.49$ & $24.44 \pm 3.09$ \\
\hline $51-60$ & 108 & $154.68 \pm 5.16$ & $62.45 \pm 10.70$ & $26.23 \pm 4.22$ & $51-60$ & 98 & $167.16 \pm 5.66$ & $68.68 \pm 12.22$ & $24.53 \pm 3.67$ \\
\hline $61-70$ & 106 & $153.56 \pm 6.01$ & $59.89 \pm 11.24$ & $25.40 \pm 4.07$ & $61-70$ & 90 & $168.33 \pm 7.61$ & $67.84 \pm 12.89$ & $23.99 \pm 2.98$ \\
\hline $71-86$ & 69 & $150.07 \pm 5.83$ & $55.81 \pm 12.35$ & $24.91 \pm 5.89$ & $71-83$ & 51 & $165.75 \pm 6.39$ & $65.14 \pm 9.01$ & $23.56 \pm 3.02$ \\
\hline
\end{tabular}

$B M I$ body mass index 
Table 2 Age-related change in BMD in Indian women in comparison to the manufacturer's BMD values

\begin{tabular}{|c|c|c|c|c|c|c|c|}
\hline \multirow[t]{2}{*}{ Skeletal site and age in years } & \multicolumn{2}{|c|}{ Present study* } & \multicolumn{2}{|c|}{ Manufacturer's normal database** } & \multirow[t]{2}{*}{$T$ score } & \multirow[t]{2}{*}{ Difference $(\%)$} & \multirow[t]{2}{*}{$P$ value } \\
\hline & Mean & $\mathrm{SD}$ & Mean & SD & & & \\
\hline \multicolumn{8}{|l|}{ Total hip } \\
\hline $20-30$ & 0.904 & $0.092^{\mathrm{b}, \mathrm{c}}$ & 0.970 & 0.130 & -7.44 & $-0.066(-6.80)$ & $0.0001 * * *$ \\
\hline $31-40$ & 0.987 & $0.121^{\mathrm{d}}$ & 0.990 & 0.130 & -0.59 & $-0.003(-0.30)$ & $0.556 \mathrm{NS}$ \\
\hline $41-50$ & 0.922 & $0.111^{\mathrm{c}}$ & 0.976 & 0.130 & -5.20 & $-0.054(-5.53)$ & $0.0001 * * *$ \\
\hline $51-60$ & 0.861 & $0.118^{\mathrm{b}}$ & 0.927 & 0.130 & -4.74 & $-0.066(-7.11)$ & $0.0001 * * *$ \\
\hline $61-70$ & 0.852 & $0.128^{\mathrm{b}}$ & 0.896 & 0.130 & -9.25 & $-0.044(-4.91)$ & $0.0001 * * *$ \\
\hline $71-86$ & 0.738 & $0.097^{\mathrm{a}}$ & 0.781 & 0.130 & -14.94 & $-0.043(-5.5)$ & $0.0001 * * *$ \\
\hline \multicolumn{8}{|l|}{ Femoral neck } \\
\hline $20-30$ & 0.871 & $0.091^{\mathrm{c}}$ & 0.956 & 0.120 & -9.64 & $-0.085(-8.89)$ & $0.0001^{* * *}$ \\
\hline $31-40$ & 0.967 & $0.107^{\mathrm{d}}$ & 0.965 & 0.120 & +0.16 & $+0.002(+0.20)$ & $0.876 \mathrm{NS}$ \\
\hline $41-50$ & 0.868 & $0.111^{\mathrm{c}}$ & 0.941 & 0.120 & -6.94 & $-0.073(-7.75)$ & $0.0001 * * *$ \\
\hline $51-60$ & 0.801 & $0.114^{\mathrm{b}}$ & 0.871 & 0.120 & -6.02 & $-0.070(-8.03)$ & $0.0001 * * *$ \\
\hline $61-70$ & 0.750 & $0.115^{\mathrm{b}}$ & 0.801 & 0.120 & -0.93 & $-0.051(-6.36)$ & $0.356 \mathrm{NS}$ \\
\hline $71-86$ & 0.682 & $0.090^{\mathrm{a}}$ & 0.741 & 0.120 & -4.69 & $-0.059(-7.96)$ & $0.0001 * * *$ \\
\hline \multicolumn{8}{|l|}{ Femur Ward's } \\
\hline $20-30$ & 0.787 & $0.094^{\mathrm{d}, \mathrm{e}}$ & 0.897 & 0.130 & -12.22 & $-0.11(-12.26)$ & $0.0001 * * *$ \\
\hline $31-40$ & 0.837 & $0.128^{\mathrm{e}}$ & 0.886 & 0.130 & -3.72 & $-0.049(-5.53)$ & $0.0001 * * *$ \\
\hline $41-50$ & 0.727 & $0.125^{\mathrm{d}}$ & 0.840 & 0.130 & -9.45 & $-0.113(-13.45)$ & $0.0001^{* * *}$ \\
\hline $51-60$ & 0.633 & $0.133^{\mathrm{c}}$ & 0.740 & 0.130 & -7.98 & $-0.107(-14.46)$ & $0.0001 * * *$ \\
\hline $61-70$ & 0.560 & $0.138^{\mathrm{b}}$ & 0.644 & 0.130 & -6.02 & $-0.084(-13.04)$ & $0.001 * *$ \\
\hline $71-86$ & 0.476 & $0.070^{\mathrm{a}}$ & 0.518 & 0.130 & -3.27 & $-0.042(-8.10)$ & $0.001 * *$ \\
\hline \multicolumn{8}{|l|}{ Femur trochanter } \\
\hline $20-30$ & 0.697 & $0.077^{\mathrm{c}, \mathrm{b}}$ & 0.754 & 0.110 & -7.56 & $-0.057(-7.55)$ & $0.0001^{* * *}$ \\
\hline $31-40$ & 0.790 & $0.118^{\mathrm{d}}$ & 0.785 & 0.110 & +0.34 & $+0.005(+0.63)$ & $0.737 \mathrm{NS}$ \\
\hline $41-50$ & 0.723 & $0.100^{\mathrm{c}, \mathrm{b}}$ & 0.780 & 0.110 & -5.84 & $-0.057(-7.30)$ & $0.0001 * * *$ \\
\hline $51-60$ & 0.683 & $0.113^{\mathrm{b}}$ & 0.742 & 0.110 & -5.16 & $-0.059(-7.95)$ & $0.0001 * * *$ \\
\hline $61-70$ & 0.668 & $0.109^{\mathrm{b}}$ & 0.699 & 0.110 & -9.54 & $-0.031(-4.43)$ & $0.0001^{* * *}$ \\
\hline $71-86$ & 0.589 & $0.080^{\mathrm{a}}$ & 0.641 & 0.110 & -4.54 & $-0.052(-8.11)$ & $0.0001^{* * *}$ \\
\hline \multicolumn{8}{|l|}{ Lateral spine } \\
\hline $20-30$ & 0.654 & $0.108^{\mathrm{b}}$ & 0.768 & 0.120 & -11.18 & $-0.114(-14.84)$ & $0.0001 * * *$ \\
\hline $31-40$ & 0.712 & $0.126^{\mathrm{b}}$ & 0.767 & 0.120 & -4.29 & $-0.055(-7.17)$ & $0.0001 * * *$ \\
\hline $41-50$ & 0.662 & $0.142^{\mathrm{b}}$ & 0.706 & 0.120 & -3.23 & $-0.044(-6.23)$ & $0.001 * *$ \\
\hline $51-60$ & 0.560 & $0.121^{\mathrm{a}}$ & 0.618 & 0.120 & -4.78 & $-0.058(-9.38)$ & $0.0001 * * *$ \\
\hline $61-70$ & 0.508 & $0.152^{\mathrm{a}}$ & 0.443 & 0.120 & +4.31 & $+0.065(+14.67)$ & $0.0001 * * *$ \\
\hline $71-86$ & 0.503 & $0.167^{\mathrm{a}}$ & 0.475 & 0.120 & +1.36 & $+0.028(+5.89)$ & $0.177 \mathrm{NS}$ \\
\hline \multicolumn{8}{|l|}{ Radius 33\% } \\
\hline $20-30$ & 0.784 & $0.672^{\mathrm{d}, \mathrm{e}}$ & 0.888 & 0.089 & -16.49 & $-0.104(-11.71)$ & $0.0001^{* * *}$ \\
\hline $31-40$ & 0.826 & $0.058^{\mathrm{e}}$ & 0.888 & 0.089 & -10.65 & $-0.062(-6.98)$ & $0.0001 * * *$ \\
\hline $41-50$ & 0.784 & $0.070^{\mathrm{d}, \mathrm{e}}$ & 0.888 & 0.089 & -16.23 & $-0.104(-11.71)$ & $0.0001 * * *$ \\
\hline $51-60$ & 0.723 & $0.087^{\mathrm{c}}$ & 0.863 & 0.089 & -21.52 & $-0.140(-16.22)$ & $0.0001 * * *$ \\
\hline $61-70$ & 0.668 & $0.117^{\mathrm{b}}$ & 0.775 & 0.089 & -19.22 & $-0.107(-13.81)$ & $0.0001 * * *$ \\
\hline $71-86$ & 0.583 & $0.114^{\mathrm{a}}$ & 0.684 & 0.089 & -10.81 & $-0.101(-14.77)$ & $0.0001 * * *$ \\
\hline \multicolumn{8}{|l|}{ Radius UD } \\
\hline $20-30$ & 0.521 & $0.100^{\mathrm{e}}$ & 0.469 & 0.045 & +5.55 & $+0.052(+11.09)$ & $0.0001 * * *$ \\
\hline $31-40$ & 0.468 & $0.058^{\mathrm{d}}$ & 0.469 & 0.045 & -0.18 & $-0.001(-0.21)$ & $0.855 \mathrm{NS}$ \\
\hline $41-50$ & 0.431 & $0.056^{\mathrm{c}}$ & 0.469 & 0.045 & -7.30 & $-0.038(-8.10)$ & $0.0001 * * *$ \\
\hline $51-60$ & 0.380 & $0.058^{\mathrm{b}}$ & 0.448 & 0.045 & -11.85 & $-0.068(-15.18)$ & $0.0001 * * *$ \\
\hline $61-70$ & 0.371 & $0.119^{\mathrm{b}}$ & 0.412 & 0.045 & -14.45 & $-0.041(-9.95)$ & $0.0001 * * *$ \\
\hline $71-86$ & 0.314 & $0.077^{\mathrm{a}}$ & 0.367 & 0.045 & -5.42 & $-0.053(-14.44)$ & $0.0001 * * *$ \\
\hline
\end{tabular}

Comparison of means was done using one-way analysis of variance (ANOVA) with age as varying factor followed by Tukey's test for significance; values followed by different letters $(\mathrm{a}, \mathrm{b}, \mathrm{c}, \mathrm{d}, \mathrm{e})$ are statistically different at $P<0.0001$

$N S$ statistically nonsignificant

*As calculated by the formula provided by the manufacturer based on the age and weight of the individual concerned

**SD values as provided by the manufacturer $[15,16$, and personal communication] 
Table 3 Regression of BMD on age at different skeletal sites in the respective peak bone mass age group of female and male subjects

\begin{tabular}{llll}
\hline BMD & Regression within peak group & $R^{2}$ & $P$ value \\
\hline Female & & & \\
Wrist & $y=0.003 x^{2}-0.0994 x+2.325$ & 0.0609 & $>0.05$ \\
Radius UD & $y=-0.004 x^{2}+0.0936 x-1.009$ & 0.0713 & $>0.05$ \\
Hip & $y=0.0016 x^{2}-0.124 x+3.3014$ & 0.0474 & $>0.05$ \\
Spine & $y=0.0004 x^{2}-0.038 x+1.575$ & 0.0644 & $>0.05$ \\
Neck & $y=0.001 x^{2}-0.0826 x+2.6016$ & 0.0812 & $>0.05$ \\
Wards & $y=-0.0006 x^{2}+0.0314 x+0.4909$ & 0.0704 & $>0.05$ \\
Trochanter & $y=-0.0004 x^{2}+0.0237 x+0.4061$ & 0.0065 & $>0.05$ \\
Male & & & \\
Wrist & $y=-0.0026 x^{2}+0.1211 x-0.0839$ & 0.0849 & $>0.05$ \\
Radius UD & $y=0.0018 x^{2}-0.1217 x+2.4829$ & 0.0984 & $>0.05$ \\
Hip & $y=-0.0016 x^{2}+0.0634 x+0.4151$ & 0.0565 & $>0.05$ \\
Spine & $y=0.0057 x^{2}-0.3895 x+1.3848$ & 0.0874 & $>0.05$ \\
Neck & $y=-0.0025 x^{2}+0.1139 x-0.2191$ & 0.0441 & $>0.05$ \\
Wards & $y=-0.0029 x^{2}+0.1267 x-0.4008$ & 0.0643 & $>0.05$ \\
Trochanter & $y=0.0002 x^{2}-0.0219 x+0.3087$ & 0.0810 & $>0.05$ \\
\hline
\end{tabular}

femoral neck, and trochanter. The mean BMD values in Indian women were $0.3-14.5 \%$ lower at the total hip and its components from the Caucasian Lunar BMD database supplied by the manufacturer. However, when peak BMD values of total hip and its components obtained for this study population were compared with the reference peak BMD values for Caucasian women provided by the manufacturer, significant difference $(5.5 \%, P<0.001)$ was observed only at the Ward's triangle.

$T$ scores for total hip and its components calculated using peak BMD and SD values of this study population were different from those obtained using the Caucasian BMD means and SD provided by the manufacturer (Table 4). The percent postmenopausal population classified as osteoporotic $(T$ score $<-2.5)$ and osteopenic $(T$ score $>-2.5$ to $<-1)$ differed substantially depending on the skeletal site of interest where BMD was determined. Of the postmenopausal women, $61.2 \%$ was characterized as osteoporotic at the Ward's triangle using the Caucasian Lunar BMD database, whereas only $30.1 \%$ was characterized as osteoporotic using the reference range for the Indian population defined in this study. Higher peak BMD value in Indian women at the femoral neck led to a larger percentage of women classified as osteoporotic with the Indian reference values defined in this study than with the Caucasian Lunar BMD database $(26.6 \%$ versus $20.7 \%)$. At the trochanter region, $T$ scores calculated using the Indian peak BMD values obtained in this study resulted in marked decrease in the number of postmenopausal women classified as osteoporotic $(5.3 \%$ versus $10.5 \% ; P<0.05)$ in the $41-50$ years age group and $(11.6 \%$ versus $18.8 \%$, statistically nonsignificant) in 70-86 year age group than the manu- facturer's reference value. The difference in other age groups with the two reference ranges was not significant. A $2.8 \%$ (statistically nonsignificant) decrease in osteoporotics in women aged 50-70 years was observed at the total hip with the newly derived Indian peak BMD values when compared to the manufacturer's reference values. There was no difference in other age groups.

The cut off values for osteoporosis of the total hip, femoral neck, Ward's triangle, and trochanter in women using the Indian reference values were $0.685,0.699,0.517$, and $0.495 \mathrm{~g} / \mathrm{cm}^{2}$, respectively. The corresponding values according to manufacturer's reference database were 0.665 , $0.665,0.572$, and $0.510 \mathrm{~g} / \mathrm{cm}^{2}$, respectively.

\section{Lumbar spine}

At the lumbar spine, BMD among Indian women remained stable between ages 20 and 50 years and declines thereafter (Table 2). Though there was no statistically significant difference in the BMD values for ages 20-50 years, peak BMD (i.e., the highest mean BMD at a particular site) was identified in the $31-40$ years age group. The best-fitting curve was a polynomial equation of the second degree $\left(R^{2}=\right.$ $0.2543, P<0.01$; Fig. 1e). The mean decrease between the fourth and fifth decade was $15 \%$ after which there was a nonsignificant decline in BMD with increasing age. The decrease of BMD between the age of peak BMD and 86 years in women was $29 \%$ (average of $5.8 \%$ per decade). Compared to the manufacturer's Lunar reference values, BMD in Indian women was $6.2-14.8 \%(P<0.001)$ lower at the lumbar spine between ages 20 and 60 years. However, the BMD of Indian women for the decade beginning at 61 years was $14.7 \%$ higher $(P<0.0001)$ than Lunar reference values for this age group. The difference was nonsignificant for the 70-86 years age group; $6.0 \%$ more postmenopausal Indian women were diagnosed with osteoporosis using Lunar reference peak BMD and SD values than newly derived Indian peak BMD and SD values obtained in this study for the calculation of $T$ scores (Table 4). The cut off value for osteoporosis at this site in women was $0.397 \mathrm{~g} /$ $\mathrm{cm}^{2}$ compared to $0.468 \mathrm{~g} / \mathrm{cm}^{2}$ with the Lunar reference values.

\section{Forearm}

The best-fitting curve for the forearm was a polynomial function of the second degree (Fig. 1f-g). Peak BMD was achieved in the age group 31-40 years at the radius 33\% and 20-30 years at the radius UD (Tables 2 and 3), followed by a decrease with age $\left(R^{2}=0.4555, P<0.001\right.$ and $R^{2}=0.2853, P<0.01$, respectively). The decrease in BMD between the age of peak BMD and 86 years was $29.4 \%$ for radius $33 \%$ (average of $5.8 \%$ per decade) and $39.7 \%$ for 
Fig. 1 Regression equations and trend lines of BMD of total hip (a), femoral neck (b),

Ward's triangle (c), trochanter (d), lateral spine (e), radius 33\% (f), and radius UD $(\mathbf{g})$ in relation to age (20-86 years) in Indian women
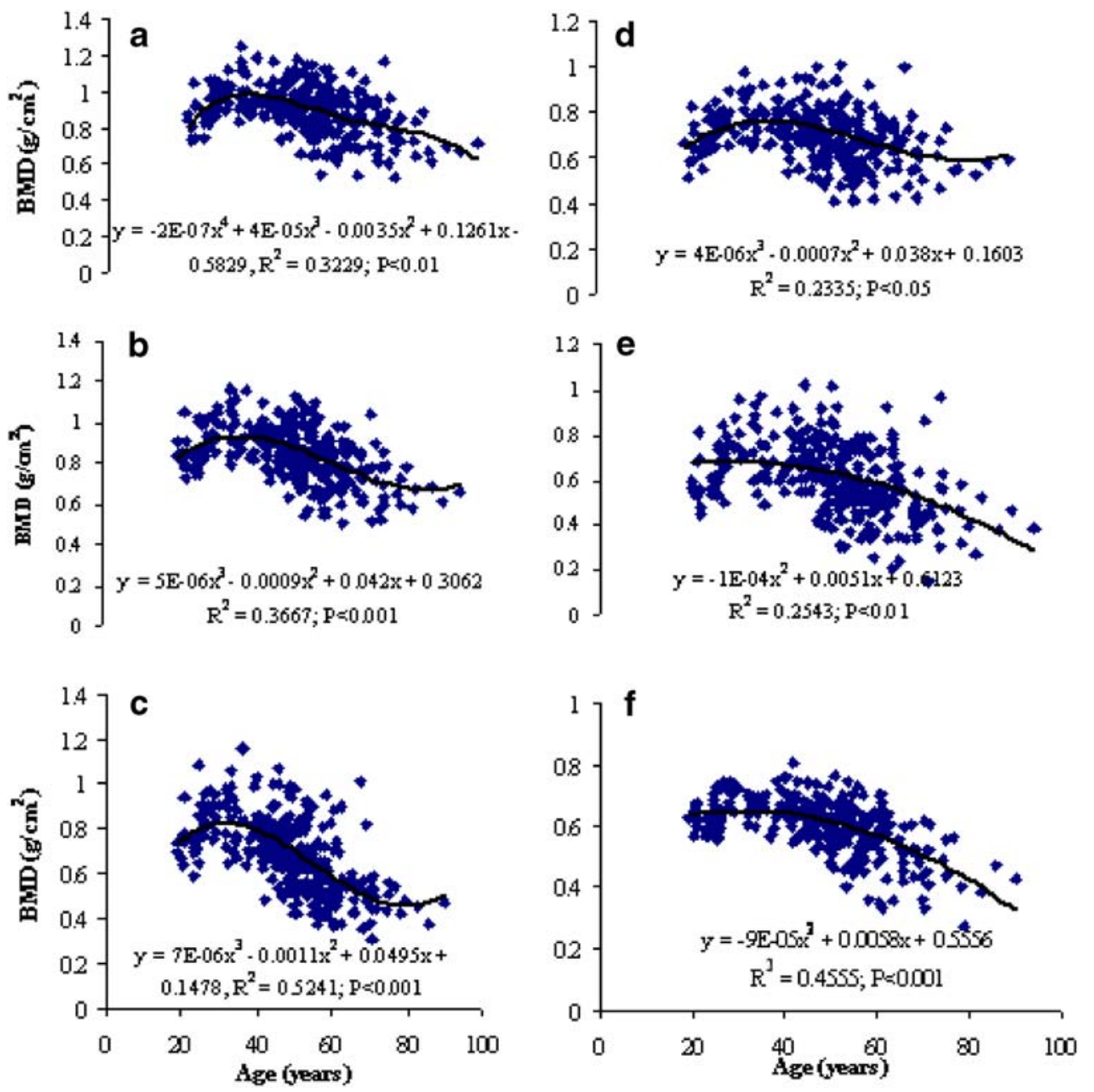

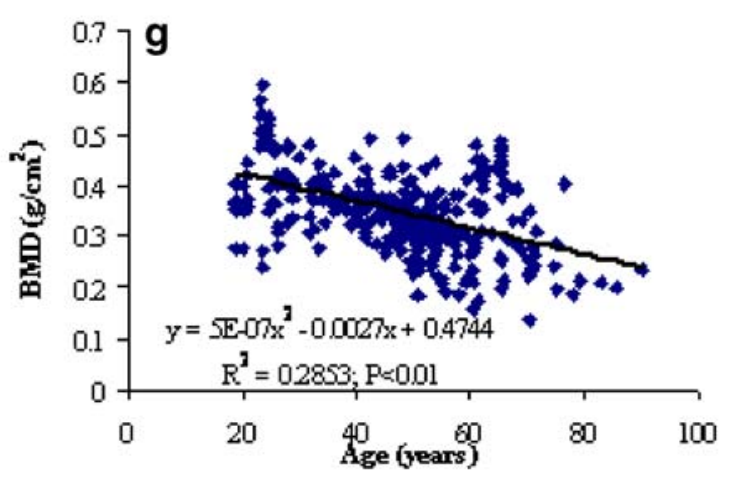

radius UD (average of $6.6 \%$ per decade). Compared to Lunar reference values, BMD in Indian women was $6.9-16.2 \%$ lower at radius $33 \%$ and $0.2-15.2 \%$ lower at the radius UD (Table 2). At radius 33\%, the peak BMD of the study population was $6.9 \%$ lower than the reference population. However, smaller variance in the study population compared to the Caucasian population ( 0.058 versus $0.08875 \mathrm{SD})$ resulted in $3.2 \%$ more postmenopausal women classified as osteoporotic with the Indian than Caucasian reference values.
At the radius UD, peak BMD of study population was $11.1 \%$ higher than the reference Caucasian population and the incidence of osteoporosis decreased by $22.4 \%$ using the Indian peak BMD and SD values obtained in this study (Table 4). The cut off values for osteoporosis of the radius $33 \%$ and radius UD site using the Indian reference values were 0.681 and $0.271 \mathrm{~g} / \mathrm{cm}^{2}$, respectively. The corresponding values according to manufacturer's reference database were 0.665 and $0.356 \mathrm{~g} / \mathrm{cm}^{2}$, respectively. 
Table 4 Prevalence of osteoporosis and osteopenia at different skeletal sites in postmenopausal Indian women using the Indian versus the Caucasian peak BMD values

\begin{tabular}{|c|c|c|c|c|c|c|c|c|c|}
\hline \multirow{3}{*}{$\begin{array}{l}\text { Skeletal } \\
\text { site }\end{array}$} & \multirow[t]{3}{*}{ Study } & \multicolumn{8}{|l|}{ Age in years } \\
\hline & & \multicolumn{2}{|l|}{$41-50$} & \multicolumn{2}{|l|}{$51-60$} & \multicolumn{2}{|l|}{$61-70$} & \multicolumn{2}{|l|}{$71-86$} \\
\hline & & Osteoporotic & Osteopenic & Osteoporotic & Osteopenic & Osteoporotic & Osteopenic & Osteoporotic & Osteopenic \\
\hline \multirow[t]{2}{*}{ Total hip } & Present study & 7.89 & 42.11 & 7.48 & 44.86 & 11.32 & 35.85 & 28.99 & 65.22 \\
\hline & $\begin{array}{l}\text { Caucasian Lunar } \\
\text { BMD Database }\end{array}$ & 7.89 & 47.37 & 10.28 & 44.86 & 14.15 & 35.85 & 28.99 & 65.22 \\
\hline \multirow[t]{2}{*}{ Femoral neck } & Present study & 7.89 & 62.65 & 19.63 & 47.66 & 17.92 & 49.06 & $60.87 * *$ & $31.88^{*}$ \\
\hline & $\begin{array}{l}\text { Caucasian Lunar } \\
\text { BMD database }\end{array}$ & 5.26 & 65.79 & 13.08 & 53.27 & 15.09 & 40.57 & 49.28 & 43.48 \\
\hline \multirow[t]{2}{*}{ Femur Ward's } & Present study & $10.53 * *$ & $60.53 *$ & $15.89^{* *}$ & $58.88^{*}$ & $27.36^{* *}$ & $58.49 * *$ & $66.67 * *$ & $33.33 * *$ \\
\hline & $\begin{array}{l}\text { Caucasian Lunar } \\
\text { BMD database }\end{array}$ & 31.58 & 47.37 & 41.12 & 41.12 & 79.25 & 12.26 & 92.75 & 7.25 \\
\hline \multirow{2}{*}{$\begin{array}{l}\text { Femur } \\
\text { trochanter }\end{array}$} & Present study & $5.26^{*}$ & 42.11 & 4.67 & 44.86 & 10.38 & 33.96 & 11.59 & 63.77 \\
\hline & $\begin{array}{l}\text { Caucasian Lunar } \\
\text { BMD database }\end{array}$ & 10.53 & 39.47 & 6.54 & 43.93 & 10.38 & 36.79 & 18.84 & 62.32 \\
\hline \multirow[t]{2}{*}{ Lateral spine } & Present study & $7.89 *$ & $44.74 *$ & 8.41 & 59.81 & 18.87 & 49.06 & 28.99 & 50.72 \\
\hline & $\begin{array}{l}\text { Caucasian Lunar } \\
\text { BMD database }\end{array}$ & 18.42 & 34.21 & 12.15 & 58.88 & 22.64 & 43.40 & 34.78 & 50.72 \\
\hline \multirow[t]{2}{*}{ Radius 33\% } & Present study & 10.53 & $50.00 *$ & 22.43 & $43.93^{*}$ & 45.28 & 34.91 & 75.00 & 25.00 \\
\hline & $\begin{array}{l}\text { Caucasian Lunar } \\
\text { BMD database }\end{array}$ & 7.89 & 68.42 & 15.89 & 63.55 & 41.51 & 45.28 & 75.00 & 25.00 \\
\hline \multirow[t]{2}{*}{ Radius UD } & Present study & $0.00 * *$ & 52.63 & $4.67 *$ & $73.83 *$ & $13.20^{*}$ & $28.30^{*}$ & $29.41 * *$ & $57.35 * *$ \\
\hline & $\begin{array}{l}\text { Caucasian Lunar } \\
\text { BMD database }\end{array}$ & 13.16 & 42.11 & 19.63 & 60.75 & 29.25 & 12.26 & 75.00 & 11.76 \\
\hline
\end{tabular}

Values represent the percentage of total subjects in each age group. The $T$ scores were calculated as [(BMD-peak bone mass $) / \mathrm{SD}$ peak bone mass] [14]

${ }^{*} P<0.05, * * P<0.001$, versus corresponding Caucasian Lunar BMD database (Fisher's exact $t$ test)

Male subjects

\section{Hip}

Peak BMD for the total hip and its components in Indian men, unlike women, was observed between ages 20 and 30 years (Tables 3 and 5). The best-fitting models were cubic equation for total hip $\left(R^{2}=0.0462, P>0.05\right)$ and trochanter $\left(R^{2}=0.0430, P>0.05\right)$ and quadratic equations for femoral neck $\left(R^{2}=0.1449, P<0.05\right)$ and Ward's $\left(R^{2}=0.3009, P<\right.$ 0.001 ) regions (Fig. 2a-d). Although a significant negative correlation between age and BMD of the hip and its regions was seen in men $(P<0.001)$, only BMD of femoral neck and Ward's regions was significantly negatively regressed with age (Fig. 2b-c). The BMD of total hip showed nonsignificant decline up to 70 years of age after which a decline of 5.5\% was observed. A 5.8\% decline in BMD of the trochanter region was observed between the second and the fourth decade beyond which the BMD showed nonsignificant decline. The decrease of BMD between the age of peak BMD and 83 years was highest for Ward's triangle $(32.0 \%$, i.e., $5.3 \%$ per decade) and lowest for trochanter $(8.6 \%$, i.e., $1.4 \%$ per decade). The mean BMD values in Indian men were $0.5-10.2 \%$ lower at the total hip and its components than the calculated Lunar reference values provided by the manufacturer (Table 5). Significant differences in peak BMD values of the study population and reference peak BMD values were observed at the total hip and trochanter regions $(4.5 \%, P<0.001$ and $4.4 \%, P<0.01$, respectively; Table 5). A larger proportion of Indian men $>50$ years of age was classified as osteoporotic on the basis of $T$ scores calculated using the database provided by the manufacturer than with the reference values of the present study population $(6.3 \%$ versus $1.3 \%$ at total hip; $11.3 \%$ versus $4.6 \%$ at femoral neck; $34.5 \%$ versus $19.2 \%$ at Ward's triangle; $9.2 \%$ versus $1.4 \%$ at trochanter; Table 6 ). The cut off values for osteoporosis of the total hip, femoral neck, Ward's triangle, and trochanter in men using the Indian reference values were $0.686,0.687,0.566$, and $0.574 \mathrm{~g} / \mathrm{cm}^{2}$, respectively. The corresponding values according to the manufacturer's reference database were $0.741,0.726,0.627$, and $0.629 \mathrm{~g} / \mathrm{cm}^{2}$, respectively. 
Table 5 Age-related change in BMD in Indian men in comparison to the manufacturer's BMD values

\begin{tabular}{|c|c|c|c|c|c|c|c|}
\hline \multirow[t]{2}{*}{ Skeletal site and age in years } & \multicolumn{2}{|c|}{ Present study* } & \multicolumn{2}{|c|}{ Manufacturer's normal database** } & \multirow[t]{2}{*}{$T$ score } & \multirow[t]{2}{*}{ Difference $(\%)$} & \multirow[t]{2}{*}{$P$ value } \\
\hline & Mean & $\mathrm{SD}$ & Mean & SD & & & \\
\hline \multicolumn{8}{|l|}{ Total hip } \\
\hline $20-30$ & 1.018 & $0.133^{\mathrm{b}}$ & 1.066 & 0.130 & -3.29 & $-0.048(-4.50)$ & $0.0001 * * *$ \\
\hline $31-40$ & 0.979 & $0.131^{\mathrm{b}}$ & 1.055 & 0.130 & -4.57 & $-0.076(-7.20)$ & $0.0001 * * *$ \\
\hline $41-50$ & 0.976 & $0.125^{\mathrm{b}}$ & 1.026 & 0.130 & -3.78 & $-0.050(-4.87)$ & $0.0001 * * *$ \\
\hline $51-60$ & 0.971 & $0.125^{\mathrm{b}}$ & 0.993 & 0.130 & -1.69 & $-0.022(-2.21)$ & $0.094 \mathrm{NS}$ \\
\hline $61-70$ & 0.972 & $0.103^{\mathrm{b}}$ & 0.968 & 0.130 & +0.29 & $+0.004(+0.41)$ & $0.774 \mathrm{NS}$ \\
\hline $71-83$ & 0.919 & $0.139^{\mathrm{a}}$ & 0.954 & 0.130 & -2.30 & $-0.035(-3.66)$ & $0.024 \mathrm{NS}$ \\
\hline \multicolumn{8}{|l|}{ Femoral neck } \\
\hline $20-30$ & 1.019 & $0.133^{\mathrm{c}}$ & 1.051 & 0.130 & -2.18 & $-0.032(-3.04)$ & $0.031 \mathrm{NS}$ \\
\hline $31-40$ & 0.961 & $0.117^{\mathrm{b}}$ & 1.036 & 0.130 & -4.53 & $-0.075(-7.23)$ & $0.0001 * * *$ \\
\hline $41-50$ & 0.918 & $0.127^{\mathrm{b}}$ & 0.992 & 0.130 & -5.50 & $-0.074(-7.45)$ & $0.0001 * * *$ \\
\hline $51-60$ & 0.919 & $0.148^{\mathrm{b}}$ & 0.944 & 0.130 & -1.65 & $-0.025(-2.64)$ & $0.102 \mathrm{NS}$ \\
\hline $61-70$ & 0.892 & $0.098^{\mathrm{a}, \mathrm{b}}$ & 0.904 & 0.130 & -1.05 & $-0.012(-1.32)$ & $0.297 \mathrm{NS}$ \\
\hline $71-83$ & 0.852 & $0.133^{\mathrm{a}}$ & 0.856 & 0.130 & -0.26 & $-0.004(-0.46)$ & $0.795 \mathrm{NS}$ \\
\hline \multicolumn{8}{|l|}{ Femur Ward's } \\
\hline $20-30$ & 0.941 & $0.150^{\mathrm{d}}$ & 0.952 & 0.130 & -0.65 & $-0.011(-1.15)$ & $0.515 \mathrm{NS}$ \\
\hline $31-40$ & 0.829 & $0.116^{\mathrm{c}}$ & 0.907 & 0.130 & -5.22 & $-0.078(-8.59)$ & $0.0001 * * *$ \\
\hline $41-50$ & 0.762 & $0.148^{\mathrm{b}}$ & 0.849 & 0.130 & -5.78 & $-0.087(-10.24)$ & $0.0001 * * *$ \\
\hline $51-60$ & 0.741 & $0.162^{b}$ & 0.785 & 0.130 & -2.61 & $-0.044(-5.60)$ & $0.05^{*}$ \\
\hline $61-70$ & 0.719 & $0.134^{\mathrm{b}}$ & 0.726 & 0.130 & -0.47 & $-0.007(-0.96)$ & $0.640 \mathrm{NS}$ \\
\hline $71-83$ & 0.640 & $0.165^{\mathrm{a}}$ & 0.658 & 0.130 & -1.06 & $-0.018(-2.73)$ & $0.293 \mathrm{NS}$ \\
\hline \multicolumn{8}{|l|}{ Femur trochanter } \\
\hline $20-30$ & 0.859 & $0.114^{\mathrm{b}}$ & 0.899 & 0.110 & -3.12 & $-0.040(-4.44)$ & $0.001 * *$ \\
\hline $31-40$ & 0.830 & $0.100^{\mathrm{a}, \mathrm{b}}$ & 0.904 & 0.110 & -5.68 & $-0.074(-8.18)$ & $0.0001 * * *$ \\
\hline $41-50$ & 0.809 & $0.103^{\mathrm{a}}$ & 0.888 & 0.110 & -7.19 & $-0.079(-8.89)$ & $0.0001 * * *$ \\
\hline $51-60$ & 0.816 & $0.108^{\mathrm{a}}$ & 0.865 & 0.110 & -4.31 & $-0.049(-5.66)$ & $0.0001 * * *$ \\
\hline $61-70$ & 0.815 & $0.103^{\mathrm{a}}$ & 0.849 & 0.110 & -2.93 & $-0.034(-4.00)$ & $0.001 * *$ \\
\hline $71-83$ & 0.785 & $0.134^{\mathrm{a}}$ & 0.826 & 0.110 & -2.81 & $-0.041(-4.96)$ & $0.006 \mathrm{NS}$ \\
\hline \multicolumn{8}{|l|}{ Lateral spine } \\
\hline $20-30$ & 0.778 & $0.125^{\mathrm{b}}$ & 0.964 & 0.120 & -13.42 & $-0.186(-19.29)$ & $0.0001 * * *$ \\
\hline $31-40$ & 0.847 & $0.136^{\mathrm{b}, \mathrm{c}}$ & 0.935 & 0.120 & -5.26 & $-0.088(-9.41)$ & $0.0001 * * *$ \\
\hline $41-50$ & 0.787 & $0.159^{\mathrm{b}}$ & 0.879 & 0.120 & -5.61 & $-0.092(-10.46)$ & $0.0001 * * *$ \\
\hline $51-60$ & 0.789 & $0.167^{\mathrm{b}}$ & 0.795 & 0.120 & -0.39 & $-0.006(-0.76)$ & $0.695 \mathrm{NS}$ \\
\hline $61-70$ & 0.785 & $0.144^{\mathrm{a}, \mathrm{b}}$ & 0.722 & 0.120 & +4.14 & $+0.063(+8.72)$ & $0.0001 * * *$ \\
\hline $71-83$ & 0.730 & $0.151^{\mathrm{a}}$ & 0.686 & 0.120 & +2.73 & $+0.044(+6.41)$ & $0.008 \mathrm{NS}$ \\
\hline \multicolumn{8}{|l|}{ Radius 33\% } \\
\hline $20-30$ & 0.891 & $0.085^{\mathrm{b}}$ & 1.002 & 0.100 & -12.11 & $-0.111(-11.08)$ & $0.0001 * * *$ \\
\hline $31-40$ & 10.873 & $0.139^{b}$ & 1.002 & 0.100 & -7.84 & $-0.129(-12.87)$ & $0.0001 * * *$ \\
\hline $41-50$ & 0.877 & $0.079^{\mathrm{b}}$ & 1.002 & 0.100 & -12.94 & $-0.125(-12.47)$ & $0.0001 * * *$ \\
\hline $51-60$ & 0.874 & $0.098^{\mathrm{b}}$ & 0.984 & 0.100 & -11.06 & $-0.110(-11.18)$ & $0.0001 * * *$ \\
\hline $61-70$ & 0.878 & $0.089^{\mathrm{b}}$ & 0.946 & 0.100 & -7.26 & $-0.068(-7.19)$ & $0.0001^{* * *}$ \\
\hline $71-83$ & 0.796 & $0.137^{\mathrm{a}}$ & 0.907 & 0.100 & -7.59 & $-0.111(-12.24)$ & $0.0001 * * *$ \\
\hline \multicolumn{8}{|l|}{ Radius UD } \\
\hline $20-30$ & 0.525 & $0.064^{\mathrm{c}}$ & 0.528 & 0.051 & -0.40 & $-0.003(-0.57)$ & $0.692 \mathrm{NS}$ \\
\hline $31-40$ & 0.531 & $0.065^{\mathrm{c}}$ & 0.528 & 0.051 & +0.45 & $+0.003(+0.57)$ & $0.653 \mathrm{NS}$ \\
\hline $41-50$ & 0.499 & $0.075^{\mathrm{b}}$ & 0.528 & 0.051 & -3.64 & $-0.029(-5.49)$ & $0.0001 * * *$ \\
\hline $51-60$ & 0.495 & $0.071^{\mathrm{b}}$ & 0.518 & 0.051 & -3.25 & $-0.023(-4.44)$ & $0.001 * *$ \\
\hline $61-70$ & 0.473 & $0.058^{\mathrm{a}, \mathrm{b}}$ & 0.499 & 0.051 & -4.24 & $-0.026(-5.21)$ & $0.0001 * * *$ \\
\hline $71-83$ & 0.458 & $0.093^{\mathrm{a}}$ & 0.479 & 0.051 & -2.15 & $-0.021(-4.38)$ & $0.05^{*}$ \\
\hline
\end{tabular}

Comparison of means was done using one-way ANOVA with age as varying factor followed by Tukey's test for significance; values followed by different letters (a, b, c, d) are statistically different at $P<0.01$

$N S$ statistically nonsignificant

*As calculated by the formula provided by the manufacturer based on the age and weight of the individual concerned

$* *$ SD values as provided by the manufacturer $[15,16$, and personal communication] 
Fig. 2 Regression equations and trend lines of BMD of total hip (a), femoral neck (b),

Ward's triangle (c), trochanter

(d), lateral spine (e), radius 33\%

(f), and radius UD $(\mathbf{g})$ in relation to age (20-83 years) in Indian men
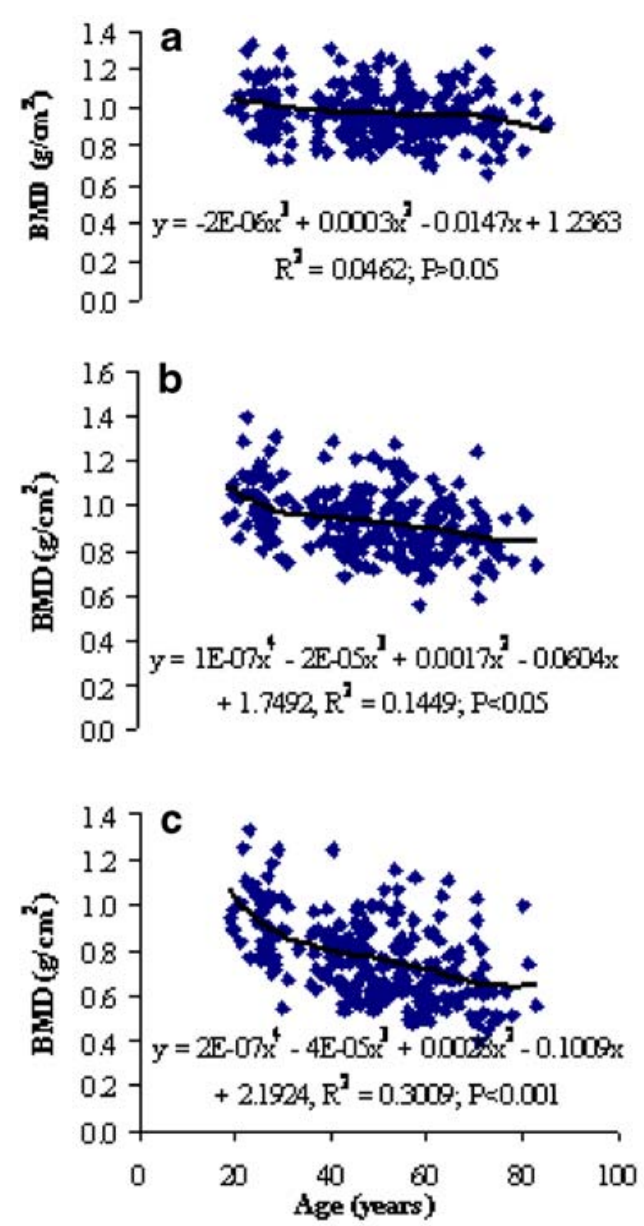
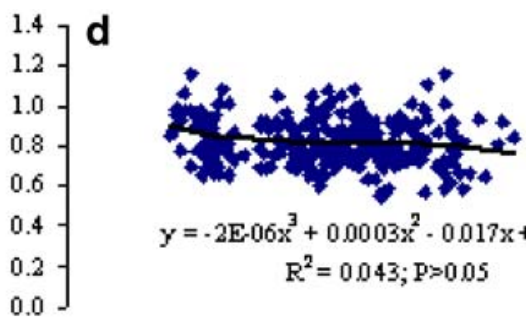

$y=-2 E-06 x^{3}+00003 x^{2}-0.017 x+1.1215$ $\mathrm{R}^{2}=0.043 ; \mathrm{P}>0.05$
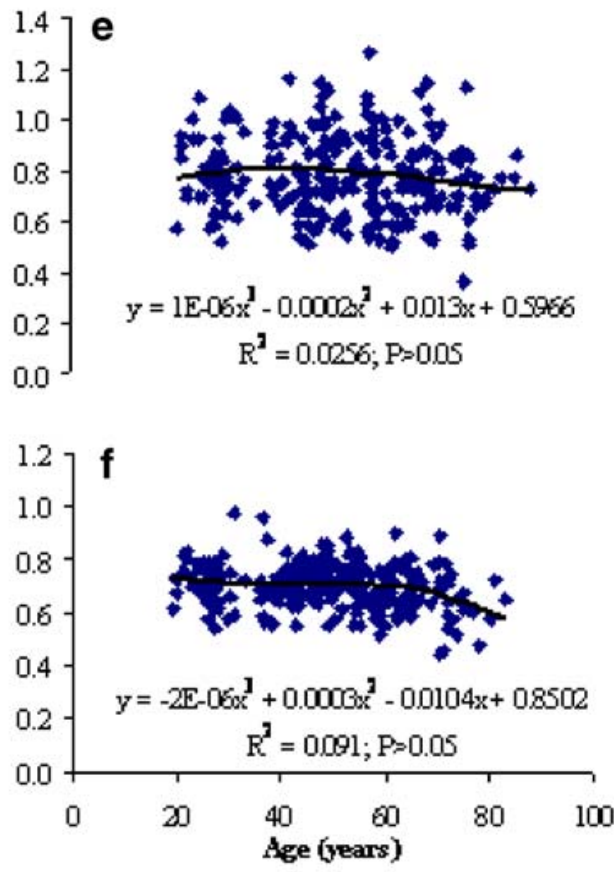

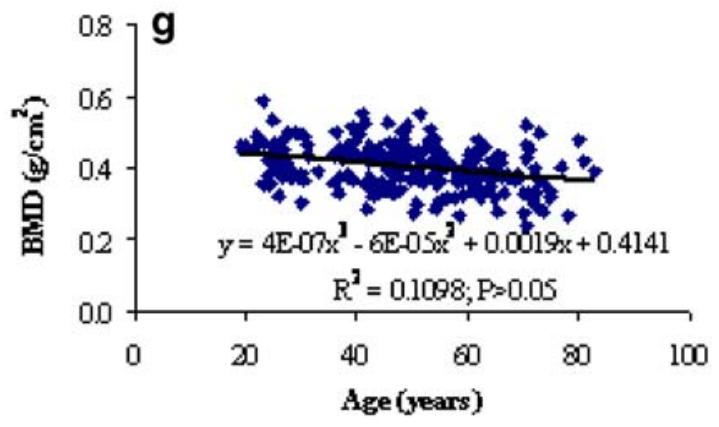

\section{Lumbar spine}

As in the case of Indian women, the highest mean BMD (viz. peak BMD) at the lumbar spine was identified in the 31-40 years age group after which the best-fitting curve was a cubic polynomial $\left(R^{2}=0.0256, P>0.05\right.$; Fig. $2 \mathrm{e}$, Table 5). A $13.8 \%$ decrease in BMD between the age of peak BMD and 83 years of age was observed at the lumbar spine. However, a negative correlation between age and BMD at lumbar spine could not be established owing to large SD values $(P>0.05)$. The proportion of men $>50$ years of age classified as osteoporotic at the lumbar spine were comparatively higher with the manufacturer's refer- ence values than with the reference values of the present study population $(8.9 \%$ versus $1.6 \%$; Table 6$)$. The cut off value for osteoporosis at this site in men was $0.507 \mathrm{~g} / \mathrm{cm}^{2}$ compared to $0.664 \mathrm{~g} / \mathrm{cm}^{2}$ with the manufacturer's Lunar reference values.

\section{Forearm}

The polynomial function of cubic regression model had the best goodness of fit at the radius $33 \%\left(R^{2}=0.091, P>0.05\right)$ and radius UD $\left(R^{2}=0.1098, P>0.05\right)$ in Indian men (Fig. 2f-g). A highly significant negative correlation of BMD with age was observed at both these sites in men $(P<$ 
Table 6 Prevalence of osteoporosis and osteopenia at different skeletal sites in Indian men using the Indian versus the Caucasian peak BMD values

\begin{tabular}{|c|c|c|c|c|c|c|c|}
\hline \multirow[t]{3}{*}{ Skeletal site } & \multirow[t]{3}{*}{ Study } & \multicolumn{6}{|l|}{ Age in years } \\
\hline & & \multicolumn{2}{|l|}{$51-60$} & \multicolumn{2}{|l|}{$61-70$} & \multicolumn{2}{|l|}{$71-83$} \\
\hline & & Osteoporotic & Osteopenic & Osteoporotic & Osteopenic & Osteoporotic & Osteopenic \\
\hline \multirow[t]{2}{*}{ Total hip } & Present study & 0.00 & $27.55^{* *}$ & 0.00 & $26.67 * *$ & $3.92 * *$ & 29.41 \\
\hline & Caucasian Lunar BMD database & 3.06 & 48.98 & 0.00 & 53.33 & 15.69 & 35.29 \\
\hline \multirow[t]{2}{*}{ Femoral neck } & Present study & 2.04 & $40.82 *$ & 0.00 & $53.33^{*}$ & $11.76^{*}$ & 43.14 \\
\hline & Caucasian Lunar BMD database & 7.14 & 53.06 & 3.33 & 67.78 & 23.53 & 37.25 \\
\hline \multirow[t]{2}{*}{ Femur Ward's } & Present study & $10.20 * *$ & $58.16^{*}$ & $12.22 * *$ & $64.44 *$ & $35.29^{*}$ & 43.14 \\
\hline & Caucasian Lunar BMD database & 25.51 & 48.98 & 28.89 & 50.00 & 49.02 & 33.33 \\
\hline \multirow[t]{2}{*}{ Femur trochanter } & Present study & 2.04 & $20.41 * *$ & 2.22 & $28.90 * *$ & $0.00 * *$ & 37.25 \\
\hline & Caucasian Lunar BMD database & 6.12 & 55.10 & 2.00 & 60.00 & 19.61 & 39.22 \\
\hline \multirow[t]{2}{*}{ Lateral spine } & Present study & $1.02 * *$ & 31.63 & $0.00 *$ & 31.11 & 3.92 & 31.37 \\
\hline & Caucasian Lunar BMD database & 10.20 & 24.49 & 6.67 & 26.67 & 9.80 & 37.25 \\
\hline \multirow[t]{2}{*}{ Radius 33\% } & Present study & $1.02 * *$ & $22.45^{* *}$ & $0.00^{*}$ & $25.56^{* *}$ & $15.69^{* *}$ & 25.49 \\
\hline & Caucasian Lunar BMD database & 13.27 & 46.94 & 6.67 & 53.33 & 35.29 & 31.37 \\
\hline \multirow[t]{2}{*}{ Radius UD } & Present study & 7.14 & 22.45 & 4.44 & $36.67^{*}$ & $15.69^{* *}$ & 39.22 \\
\hline & Caucasian Lunar BMD database & 13.27 & 20.41 & 8.89 & 48.89 & 31.37 & 31.37 \\
\hline
\end{tabular}

Values represent the percentage of total subjects in each age group. The $T$ scores were calculated as [(BMD-peak bone mass)/SD peak bone mass]] [14]

${ }^{*} P<0.05,{ }^{*} P<0.001$, versus corresponding Caucasian Lunar BMD database (Fisher's exact $t$ test)

0.001). The highest mean BMD was identified in the 20-30 years age group at this site, which was $11.1 \%$ lower than manufacturer's peak BMD value (Table 5). At the ultradistal region of the radius in males, peak BMD was achieved in the 31-40 years age group and no significant difference was observed between peak BMD value of this study population and the manufacturer's peak BMD (Table 5). The decrease of BMD between the age of peak BMD and 83 years was $10.7 \%$ (i.e., $1.8 \%$ per decade) for radius $33 \%$ and $13.8 \%$ for radius UD (i.e., $2.8 \%$ per decade). Compared to the Lunar reference values, BMD in Indian men was $7.2-12.9 \%$ lower at the radius $33 \%$ and $0.6-$ $5.5 \%$ at the radius UD (Table 5). $T$ scores calculated using peak BMD of the Indian men at the radius 33\% and ultradistal sites resulted in $5.6 \%$ and $9.1 \%$ men, respectively, being classified as osteoporotic compared to $18.4 \%$ and $17.8 \%$, respectively, with the Caucasian Lunar BMD database (Table 6). The cut off values for osteoporosis of the radius $33 \%$ and radius UD using the Indian reference values were 0.679 and $0.369 \mathrm{~g} / \mathrm{cm}^{2}$, respectively. The corresponding values according to the manufacturer's reference database were 0.751 and $0.399 \mathrm{~g} / \mathrm{cm}^{2}$, respectively.

\section{Discussion}

The results of the present study demonstrate age-related change in BMD at all measured skeletal sites in both Indian women and men. While peak BMD in women was observed between 31 and 40 years of age at the hip, spine, and radius $33 \%$ and between 20 and 30 years at the ultradistal radius, that in men was attained between 20 and 30 years at the hip and radius $33 \%$ and between 31 and 40 years at the spine and ultradistal radius. There was no regression of BMD on age in the age group showing peak BMD in both the sexes. Bone loss in both women (43\%) and men (32\%) was highest at Ward's triangle. Pertinently, a larger proportion of Indian subjects was classified as osteoporotic based on $T$ scores calculated using the Caucasian database than the newly derived Indian peak BMD values at all skeletal sites except radius 33\% and femoral neck in females above 40 years of age. The BMD normative data generated in healthy adult Indian women and men in this study might thus facilitate the clinician for effective diagnosis and management of osteoporosis in the Indian population.

Based on currently available data, it is becoming increasingly apparent that there are significant differences in BMD between various racial groups. Assessment of risk of osteoporosis in Asian women by comparing their BMD with the reference Caucasian population may have limited validity primarily because of the influence of skeletal size on such measurements. Moreover, suitable diagnostic cut off values for men, too, are less well-defined and the same absolute values for BMD used for women are used for men [11]. Since locally derived reference values are important to avoid false-positive or false-negative findings during workup in patients evaluated for osteoporosis [13], BMD 
referent databases have been created for Taiwanese [27], Chinese, Japanese [28, 29], Spanish [30], Swedish [31], and Italian [32] populations. A few studies from India have reported lower mean spinal and hip BMD in Indian women compared to the reference North American and European population [17-20]. These studies were based on BMD measurements using the Hologic QDR densitometer. Different densitometers may have different ranges of scan for different bone sites, for which adequate cross calibration may not be possible. Moreover, while standardized BMD has been proposed for comparison of spine between densitometers of different manufactures, BMD values at the hip sites (except total hip) are still not interchangeable [27].

In comparison to Caucasian women, Indian women in the present study showed significantly lower BMD at all measured skeletal sites across the spectrum of age groups. The age range at which peak BMD attained in Indian females in the present study was 31-40 years at all skeletal sites except radius UD where peak BMD occurred in the 20-30 years age group. In a previous study on Indian women [17] using the Hologic QDR densitometer, peak BMD at the total hip, femoral neck, and Ward's region was reported to occur in the 20-29 years age group. Calculated mean BMD values based on the data provided by Lunar indicate that the peak BMD in the referent Caucasian population occurs in the age group of 20-30 years in the case of radius $33 \%$, radius UD, Ward's triangle, and lateral spine and in the age group of 31-40 years at the total hip, femoral neck, and trochanter. Peak bone mass in Indian females was significantly lower at Ward's and lateral spine compared to the manufacturer's referent population. As a result, the prevalence of osteoporosis at these sites was significantly higher using the manufacturer's database in comparison with the normative data generated for Indian women in this study. The lower spinal BMD observed in this study is in accordance with that observed for the immigrant Indo-Asian women compared to Caucasian population [33]. However, since we have measured areal BMD in our population, it remains unclear whether true volumetric BMD or bone mineral apparent density in grams per cubic centimeter was lower among Indian women than Caucasian women. Estimated volumetric BMD derived from the calculation of anteroposterior and lateral spine BMD data showed strong correlation with lateral spine than anteroposterior spine in Taiwanese men [27].

BMD of lumbar vertebrae in Indian women was found to be virtually constant between 20 and 50 years of age and declined thereafter, which is in accordance with other similar studies [30-32]. It might reflect the inability of this cross-sectional study to show a slight premenopausal decrease in BMD evident in longitudinal studies [34,
35]. Decrease in BMD of the lateral spine between 51 and 86 years of age observed in the present study was statistically nonsignificant. We also did not observe an increase in BMD of the lumbar vertebrae in women $>70$ years of age as also reported by other investigators [36, 37]. Pertinently, the lateral view of the spine [27] as evaluated in this study more likely reflects age-related decrease of cancellous bone compared to the anteroposterior view used in previous studies $[14,38]$. In the age range of 61-86 years, BMD values in this study were higher than those of the manufacturer's reference values. The possibility that these values might have been affected by the selection criteria used by the manufacturer cannot be entirely ruled out.

In Indian men, BMD at the lumbar spine and radius UD reaches a peak in the age range of 31-40 years, whereas, at all other skeletal sites, peak BMD occurred between 20 and 30 years of age. Peak BMD for all skeletal sites were 1.9$15.9 \%$ higher in Indian men than in Indian women. The prevalence of osteoporosis was higher at the distal forearm compared with the total hip as reported previously [39]. Unlike females where BMD at all skeletal sites regressed negatively with age, only BMD of the femoral neck and Ward's triangle was found to be significantly negatively regressed with age in males.

BMD in both sexes correlated negatively with age, though this was statistically highly significant at all sites in women only. In men, the negative correlation between age and BMD was nonsignificant at the lumbar spine and less significant at the total hip and trochanter compared to other sites. These findings for Indian women are similar to that reported for Austrian women [37].

Age-related bone loss between age of peak BMD and 86 years in women and 83 years in men varied according to skeletal site and was of lower magnitude in men (8.6$31.99 \%)$ than in women $(25-43 \%)$. This finding is in agreement with the previously published cross-sectional studies in Caucasian subjects [40]. Similar to previous reports $[14,39]$, decrease in BMD was steepest at Ward's triangle and smallest at the trochanter in both the sexes. Also, the use of total femur BMD identified fewer women and men as osteoporotic compared with neck and Ward's BMD because of the stronger influence of trochanteric BMD on the total femur region as suggested by Mazess and Barden [15]. Pertinently, despite showing maximum agerelated bone loss, Ward's triangle is rarely selected for the diagnosis of osteoporosis because of its inconsistency with fracture risk evaluation [27].

There is a paucity of data on the prevalence of osteoporosis in the Indian population using DEXA for estimating BMD. Most of the available reports are based on methods such as Singh's index [21], calcaneal index [22], visual assessment [4, 5], quantitative ultrasound [23], 
digital X-ray radiogrammetry [24], and quantitative computed tomography [25]. The data available with DEXA are mainly for Indian women [17, 41-43] or for certain selected population groups [44, 45]. Analysis of Indian normative data revealed that the average incidence of osteoporosis at the total hip, femoral neck, Ward's, trochanter, lateral spine, radius $33 \%$, and radius UD was $13.9 \%, 26.6 \%, 30.1 \%$, $8.0 \%, 16.0 \%, 38.3 \%$, and $11.8 \%$, respectively, for postmenopausal Indian women and $1.3 \%, 4.6 \%, 19.2 \%, 1.4 \%$, $1.7 \%, 5.6 \%$, and $9.1 \%$, respectively, for Indian men above 50 years of age. However, using the manufacturer's database, corresponding values were $15.3 \%, 20.7 \%$, $61.2 \%, 11.6 \%, 22.0 \%, 35.1 \%$, and $34.3 \%$, respectively, for postmenopausal Indian women and $6.3 \%, 11.3 \%$, $34.5 \%, 9.2 \%, 8.9 \%, 18.4 \%$, and $17.8 \%$, respectively, for Indian men above 50 years of age. While the use of the US/ European database provided by Lunar versus the Indian data generated in this study might lead to different $T$ score designations and therapeutic decisions for an individual, neither score is currently linked to relevant fracture risk data for the Indian population. These findings highlight the need to establish a quantitative relationship between BMD and fracture risk in the Indian population so that pertinent diagnostic and treatment guidelines can ultimately be established.

The findings of this study must be considered in the context of several limitations. Firstly, the prevalence of osteoporosis according to age and site is based on a definition of osteoporosis in women that is not necessarily appropriate for men. Secondly, subjects in this study were all volunteers and ambulatory and presumably healthier than the general population. Moreover, data on BMD of the anteroposterior spine, not evaluated in this study, together with that of LP spine could have potential implications for the Indian scene. Also, the study is cross-sectional rather than longitudinal and the observed BMD peaks should, therefore, be interpreted with caution. Despite these limitations, the results of the present study establish useful BMD normative data with direct relevance to the Indian population. The present study adds to our knowledge of BMD variations between populations that would recommend the use of local reference ranges for reliable interpretations of individual DEXA data.

Acknowledgements The authors thank Dr. Jeff Allen, GE Healthcare, USA for providing the Caucasian reference database on Lunar Prodigy for comparison. Mr. Mohd. Faiq, Sarkar Diagnostic Institute, Lucknow for the BMD measurements, and the Department of Science and Technology and the Ministry of Health and Family Welfare, Government of India, New Delhi for the financial support. AM thanks the Department of Science and Technology, Government of India, New Delhi for the award of Women Scientist Scheme and MMS thanks the Indian Council of Medical Research, New Delhi for the appointment as Emeritus Medical Scientist. CDRI communication no. 7429.
Conflicts of interest None.

Open Access This article is distributed under the terms of the Creative Commons Attribution Noncommercial License which permits any noncommercial use, distribution, and reproduction in any medium, provided the original author(s) and source are credited.

\section{References}

1. Gupta A (1996) Osteoporosis in India-the nutritional hypothesis. Natl Med J India 9:268-274

2. Osteoporosis Society of India (2003) Action plan osteoporosis: consensus statement of an expert group. Osteoporosis Society of India, New Delhi, pp 1-40

3. Alekel DL, Mortillaro E, Hussain EA et al (1999) Lifestyle and biologic contributors to proximal femur bone mineral density and hip axis length in two distinct ethnic groups of premenopausal women. Osteoporos Int 9:327-338

4. Sridhar CB, Ahuja MMS, Bhargava S (1970) Is osteoporosis a nutritional disease? J Assoc Phys India 18:671-676

5. Khanna P, Bhargava S (1971) Roentgen assessment of bone density in north Indian population. Indian J Med Res 59:15991609

6. Henry YM, Fustell B (1997) Race and gender differences in bone mineral density (BMD) and bone turnover (BT) in young adults. J Bone Miner Res 12(Suppl 1):S249

7. Wu XP, Liao EY, Dai RC et al (2005) Comparison of spine and femur reference data in native Chinese women from different regions of China. Osteoporos Int 16:1215-1224

8. Melton LJ III (2001) The prevalence of osteoporosis: gender and racial comparison. Calcif Tissue Int 69:179-181

9. Hou YL, Liao EY, Wu XP et al (2008) Effects of the sample size of reference population on determining BMD reference curve and peak BMD and diagnosing osteoporosis. Osteoporos Int 19:71-78

10. Lofman O, Larsson L, Toss G (2000) Bone mineral density in diagnosis of osteoporosis: reference population, definition of peak bone mass and measured site determines prevalence. J Clin Densitom 3:177-186

11. Kanis JA (2002) Diagnosis of osteoporosis and assessment of fracture risk. Lancet 359:1929-1936

12. Cummings SR, Bates D, Black DM (2002) Clinical use of bone densitometry: scientific review. JAMA 288:1889-1897

13. Haiberg M, Nielsen TL, Wrae K et al (2007) Population-based reference values for bone mineral density in young men. Osteoporos Int 18:1507-1514

14. Arlot ME, Sornay-Rendu E, Garnero P et al (1997) Apparent preand post-menopausal bone loss evaluated by DXA at different skeletal sites in women: the OFELY cohort. J Bone Miner Res 12:683-690

15. Mazess RB, Barden H (1999) Bone density of the spine and femur in adult white females. Calcif Tissue Int 65:91-99

16. Haugeberg G, Uhlig T, Falch JA et al (2000) Bone mineral density and frequency of osteoporosis in female patients with rheumatoid arthritis. Arthritis Rheum 43:522-530

17. Ravishankar U. Bone mineral density in normal Indian women: assessment by dual energy X-ray absorptiometry. In Sankaran B (ed) (2000) Osteoporosis. Supported by South East Asia Regional Office, World Health Organization, pp 120-122

18. Nangia S, Arya V, Gujral RB, Mithal A (1998) Spinal bone mineral density in normal Indian females. In: Mithal A, Rao DS, Zaidi M (eds) Metabolic bone disorders. Indian Society for Bone and Mineral Research, India, pp 213-224 
19. Arya V, Nangia S, Gujral RB, Mithal A (1998) Femoral bone mineral density in normal Indian females. In: Mithal A, Rao DS, Zaidi M (eds) Metabolic bone disorders. Indian Society for Bone and Mineral Research, India, p 215

20. Savardekar LS, Shah RS, Iddya U et al (2004) Bone density in normal Indian women: assessment by USG and DEXA. Obstet Gynaecol Today 9:772-776

21. Singh M, Nagrath AR, Maini PS (1970) Changes in trabecular pattern of the upper end of the femur as an index of osteoporosis. J Bone Jt Surg 52A:457-467

22. Sharma S, Tandon VR, Mahajan A et al (2006) Preliminary screening of osteoporosis and osteopenia in urban women from Jammu using calcaneal QUS. Indian J Med Sci 60:183-189

23. Parihar Anand L, Dialani Vandana L, Mashankar AS et al (2000) Quantitative ultrasound as a tool for assessment of bone status: an initial experience. Musculoskeletal Radiology 10:229-231

24. Pande KC (2002) Prevalence of low bone mass in healthy Indian population. J Indian Med Assoc 100:598-600

25. Suri S, Khandelwal B (2000) Bone mineral content in normal Indian females: assessment by quantitative computed tomography. In: Sankaran B (ed) Osteoporosis. WHO, New Delhi, pp 132-137

26. Khosla S, Melton LJ III, Atkinson EJ et al (2001) Relationship of serum sex steroid levels to longitudinal changes in bone density in young versus elderly men. J Clin Endocrinol Metab 86:35553561

27. Yeh LR, Chen CKH, Lai PH (2004) Normal bone mineral density in anteroposterior, lateral spine and hip of Chinese men in Taiwan: effect of age change, body weight and height. J Chin Med Assoc 64:287-295

28. Woo J, Li M, Lau E (2001) Population bone mineral density measurements for Chinese women and men in Hong Kong. Osteoporos Int 12:289-295

29. Wu XP, Liao EY, Huang G et al (2003) A comparison study of the reference curves of bone mineral density at different skeletal sites in native Chinese, Japanese and American Caucasian women. Calcif Tissue Int 73:122-132

30. Diaz-Curiel M, Carrasco de la Pena JL, Perez JH et al (1997) Study of bone mineral density in lumbar spine and femoral neck in Spanish population. Osteoporos Int 7:59-64

31. Lofman O, Larsson L, Ross I et al (1997) Bone mineral density in normal Swedish women. Bone 20:167-174

32. Pedrazzoni M, Girasole G, Bertoldo F et al (2003) Definition of population-specific DXA reference standard in Italian women: the densitometric Italian normative study (DINS). Osteopros Int 14:978-982

33. Mehta G, Taylor P, Petley G et al (2004) Bone mineral status in immigrant Indo-Asian women. Q J Med 97:95-99

34. Hui SL, Perkins AJ, Zhou L et al (2002) Bone loss at the femoral neck in premenopausal white women: effects of weight change and sex-hormone levels. J Clin Endocrinol Metab 87:1539-1543

35. Bainbridge KE, Sowers MF, Crutchfield M (2002) Natural history of bone loss over 6 years among premenopausal and early postmenopausal women. Am J Epidemiol 156:410-417

36. Liao EY, Wu XP, Deng XG et al (2002) Age-related bone mineral density, accumulated bone loss rate and prevalence of osteoporosis at multiple skeletal sites in Chinese women. Osteoporos Int $13: 669-676$

37. Kudlacek S, Schneider B, Peterlik M, Leb G et al (2003) Normative data of bone mineral density in an unselected adult Austrian population. Eur J Clin Invest 33:332-339

38. Uebelhart D, Duboeuf F, Meunier PJ et al (1990) Lateral dual photon absorptiometry: a new technique to measure the bone mineral density at the lumbar spine. J Bone Miner Res 5:525-531

39. Szulc P, Marchand F, Duboeuf F et al (2000) Cross-sectional assessment of age-related bone loss in men: the MINOS study. Bone 26:123-129

40. Krall EA, Dawson-Hughes B, Hirst K et al (1997) Bone mineral density and biochemical markers of bone turnover in healthy elderly men and women. J Gerontol 52A:M61-M67

41. Nangia S, Reddy PG, Mithal A et al (2004) Bone mineral density in healthy Asian Indian women: development of a reference database and implications for diagnosis of osteoporosis. World Congress of Osteoporosis Rio de Janeiro, 14-18 May

42. Nangia S, Reddy PG, Ramaswamy N et al (2004) Bone mineral density in healthy Indian women: development of a reference database and implications for diagnosis of osteoporosis in Indian women. American Society for Bone and Mineral Research, Adult Bone and Mineral Working Group, 1-4 October

43. Gandhi AB, Shukla AKR (2005) Evaluation of BMD of women above 40 years of age. J Obstet Gynecol India 55:265-267

44. Shatrugna V, Kulkarni B, Ajay Kumar P et al (2005) Bone status of Indian women from a low-income group and its relationship to the nutritional status. Osteoporos Int 16:1827-1835

45. Vaidya SV, Dholakia D, Yadav S (2003) An age- and sexcontrolled matched pair analysis of T-scores in ethnic Indians with hip fractures. J Orthop Surg (Hong Kong) 11:22-27 